\title{
ANGIOGRAPHIC STUDIES OF THE EXTRINSIC VASCULATURE OF THE RABBIT OVARY
}

\author{
P. O. JANSON AND P. SVENDSEN \\ Department of Physiology, University of Göteborg, and Department of Obstetrics \\ and Gynaecology and Roentgen Department II, Sahlgren's Hospital, Göteborg, Sweden
}

(Received 18th Fuly 1974)

Hysterectomy is known to increase the life-span of the CL in several mammalian species (Dobrowolski \& Hafez, 1971; Anderson, 1973) and the involvement of prostaglandins has been suggested (Pharriss, 1970; McCracken, Baird \& Goding, 1971). Total hysterectomy in the rabbit extends the life of the CL (Asdell \& Hammond, 1933) and exogenous prostaglandins cause luteolysis (Duncan \& Pharriss, 1970). Few detailed studies have been reported on the vasculature of the rabbit ovary and the present investigation was carried out to determine whether anatomical prerequisites exist for a local uterine control of luteal function.

Two groups of female albino Swedish Land rabbits, 5 to 6 months old and weighing 2.3 to $3.0 \mathrm{~kg}$, were studied. The first group (four animals) consisted of untreated animals that had not previously been mated. The mean ovarian weight in these animals was $84 \mathrm{mg}$. The second group (three animals) was given 500 i.u. HCG (Gonadex: Leo Ltd) intravenously 8 days before angiography. The ovaries of these animals contained 10 to $15 \mathrm{CL}$ and the mean ovarian weight was $192 \mathrm{mg}$ on the day of the examination.

The rabbits were anaesthetized with sodium pentobarbital (Nembutal: Abbott Ltd), given at a dose rate of $30 \mathrm{mg} / \mathrm{kg}$ intravenously, and placed on an $\mathrm{X}$-ray table. A low mid-line laparotomy was performed and the abdominal walls were pulled laterally with retractors. The small intestine was gently pulled upward and to the right and the exposed abdominal and pelvic tissues were covered with a cloth soaked in saline. Care was taken to manipulate the tissues as little as possible. A polyethylene catheter (PE 90 Intramedic: Clay Adams Ltd) was inserted into the left renal artery and the tip was advanced into the aorta. The catheter was tied in place with a ligature. In one animal, a similar catheter was introduced and secured in the right femoral artery and connected to a mercury manometer for recording the arterial blood pressure.

Lumbar angiograms were made by injecting $10 \mathrm{ml}$ of low viscosity radiopaque medium (Isopaque Cerebral: Nyegaard Ltd) for $2 \mathrm{sec}$ into the aorta by way of the left renal artery. Four exposures/sec were taken for $5 \mathrm{sec}$ beginning immediately before the start of the injection. In one animal, three exposures/sec were taken for $6 \mathrm{sec}$. Two to three consecutive series of angiograms were made for each animal. The angiograms were submitted to a photographic subtraction procedure which eliminated irrelevant structures such as bones (Ziedses des 
Plantes, 1961; Horenstein, Luanh \& Sjögren, 1964). The angiograms from the two groups of rabbits were examined, with special attention to the dimensions and topographical connections of the vessels going to and from the ovaries.

A total of eighteen series of angiograms were obtained. The average time between the first filling of the ovarian arteries and appearance of contrast in the veins was $2.7 \mathrm{sec}$ (range 2.3 to $3.0 \mathrm{sec}$ ). In the rabbit prepared for blood pressure recording in the right femoral artery, the injection of contrast into the aorta did not change the pressure $(80 \mathrm{mmHg}$ in two consecutive series of angiograms with an interval of $10 \mathrm{~min}$ ).

Arteries. Two main arteries were seen to anastomose around the ovary. One, arising from the aorta (ovarian artery), ran practically perpendicularly from the aorta towards the hilus of the ovary, while the other, arising from the internal iliac artery, ran along the uterus and the oviduct (uterine artery). The ovarian artery was of larger diameter than the uterine artery in non-pregnant and pseudopregnant rabbits (see Pl. 1, Fig. 1 and Pl. 2, Fig. 3). Both arteries had a relatively straight course except for one or two branches of the ovarian artery which were spiralling before entering the hilus. The ovarian and uterine arteries were united by two main anastomoses, present in all animals. One anastomosis was situated medial to the ovary, running between the main stem of the ovarian artery, proximal to its division into the spiral arteries, and the uterine artery at the level of the uterotubal junction. The second anastomosis ran lateral to the ovary, and connected the tubal branches of the uterine artery to a branch of the ovarian artery in the hilar region.

The ovarian and uterine arteries were filled simultaneously with contrast in pregnant and pseudopregnant animals, while the medial anastomosis was filled from two directions. The diameter of this anastomosis seemed essentially the same during the follicular phase and pseudopregnancy whereas the lateral anastomosis was more prominent in non-pregnant rabbits, in which the arteries to the oviduct could be identified. Such branches could not be demonstrated in the pseudopregnant animals.

Veins. The veins ran parallel to the ovarian and the uterine arteries. The arterial anastomoses described above were also accompanied by veins (see Pl. 1, Fig. 2 and Pl. 2, Fig. 4). The veins had a straight course and, in four of the rabbits, they were less than $1 \mathrm{~mm}$ from the corresponding artery. In three animals, they were several millimeters from the arteries (see Pl. 2, Fig. 4).

In all non-pregnant rabbits, the ovary was not stained by contrast during the capillary and early venous phase, although the veins of the oviduct and the uterus were clearly visible. In the pseudopregnant rabbits, the ovaries were stained and there was only a sparse filling of the veins of the uterus and the oviduct.

Adams, Olin \& Redman (1965), using an angiographic technique involving a selective catheterization of the ovarian artery in the rabbit, demonstrated a branching of the ovarian artery to the oviduct and to the ovary of the rabbit. Göthlin \& Carter (1969) performed an extensive X-ray mapping of the pelvic arteries of the rabbit and demonstrated anastomotic connections between the ovarian and uterine arteries. In the present study, the long series of angiograms in each animal permitted the study of the topographical relationship between 


\section{PLATE 1}
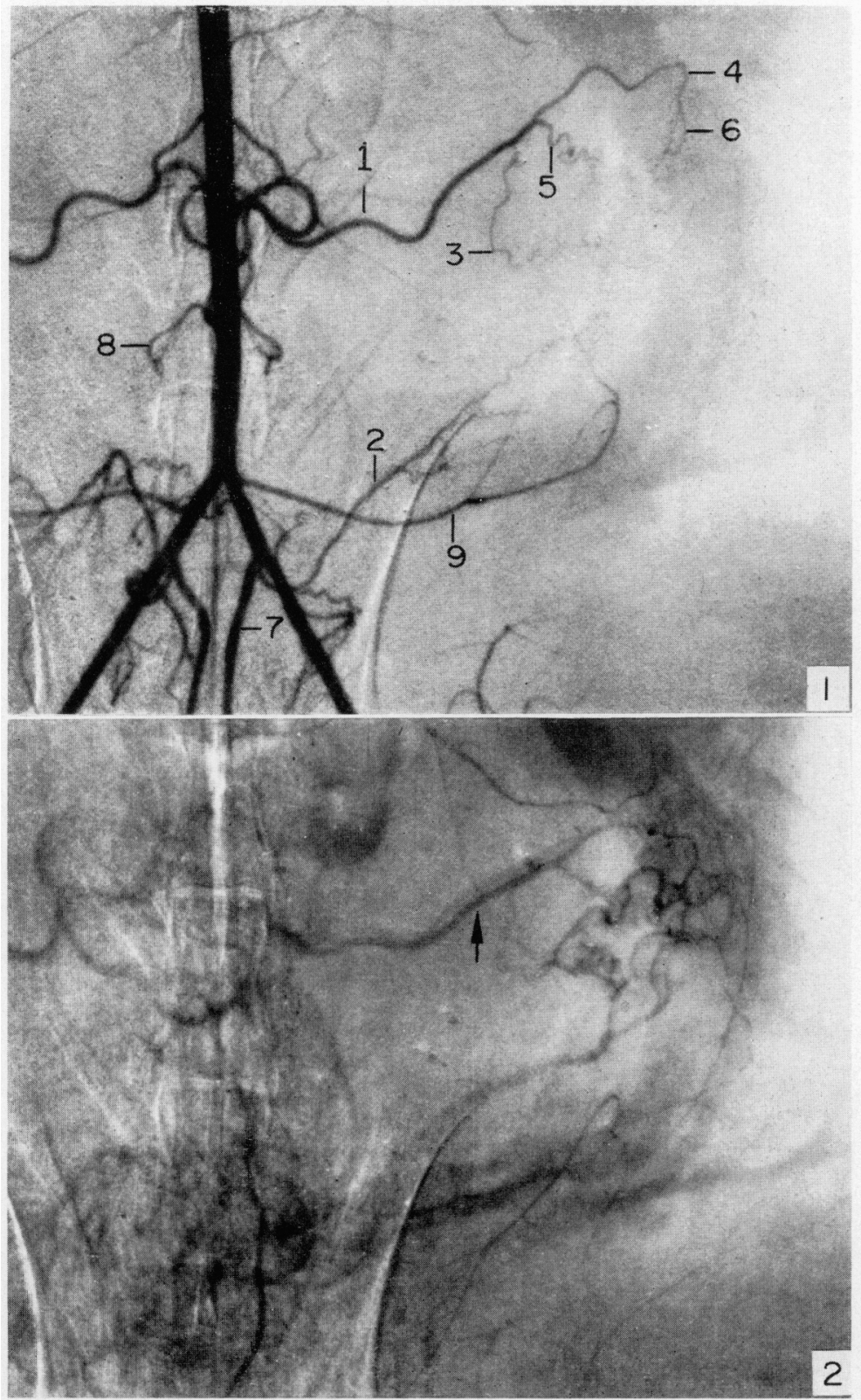

Figs 1 and 2. Angiograms in a non-pregnant rabbit; four exposures/sec, $3 \mathrm{sec}$ between exposures of Fig. 1 and Fig. 2. Figure 1 demonstrates the early arterial phase. The ovarian artery (1), arising from the abdominal aorta, is of larger diameter than the uterine artery (2) which arises from the internal iliac artery (7). Two main anastomoses of the utero-ovarian vessels are visible, one medial (3) and one lateral (4). A spiral artery (5) is running towards the hilus of the ovary. An arcade (6) to the oviduct is filled from the lateral anastomosis. The lumbar (8) and ileolumbar (9) arteries arise directly from the abdominal aorta. Figure 2 demonstrates the capillary and early venous phase in the same rabbit. The artery and vein (arrowed) can be seen running parallel to each other, the vein caudal to the artery. The ovary is not stained by contrast but the veins along the oviduct and the uterus are prominent.

(Facing p. 176) 
PI.ATE 2

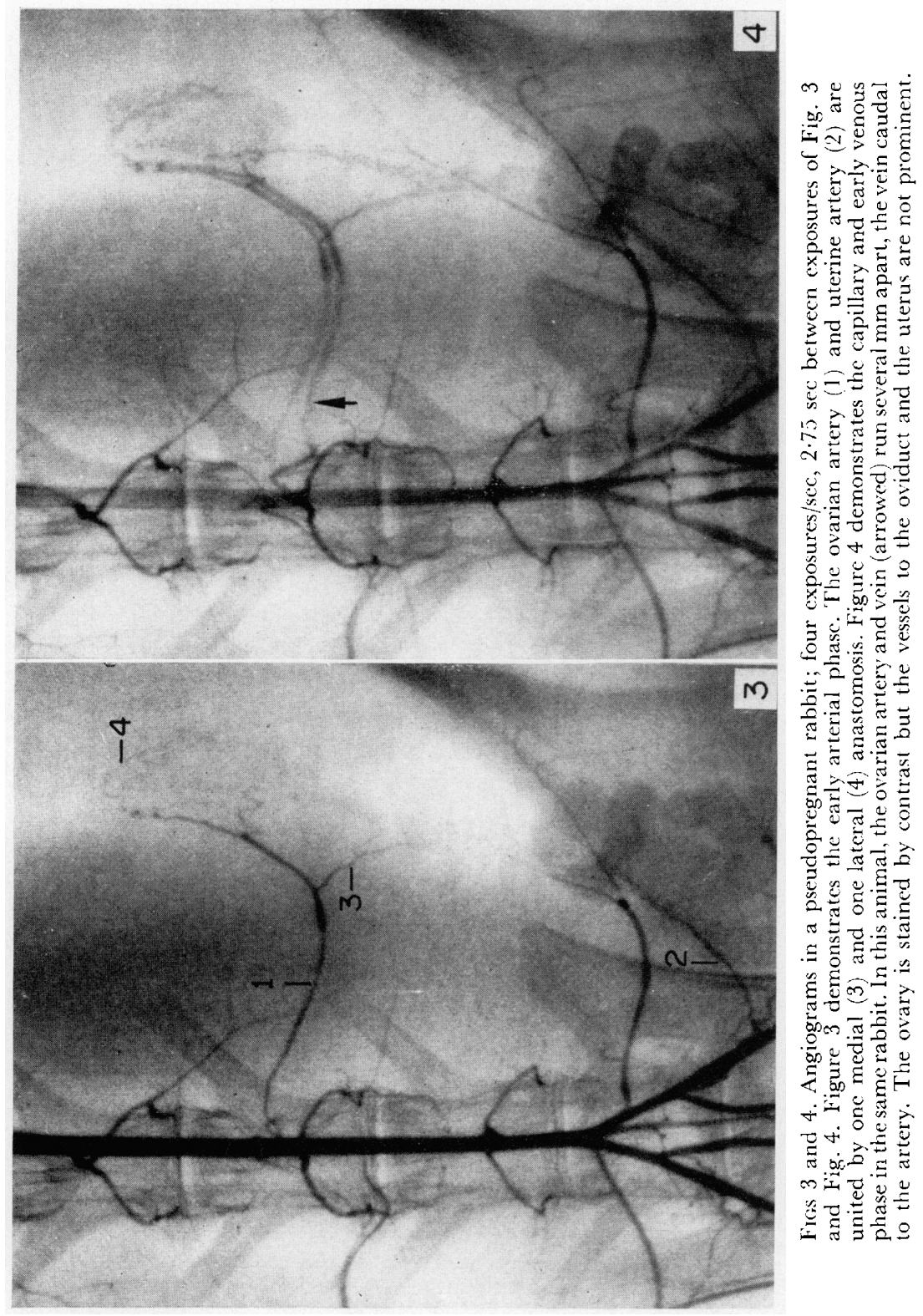

(Facing p. 177) 
arteries and veins, and indicated some dynamic aspects of the ovarian circulation.

Contrast staining of the ovaries was seen only in the rabbits with $\mathrm{CL}$, indicating a high blood flow rate during the luteal phase (see Novy \& Cook, 1973; Ahrén, Janson \& Selstam, 1974). On the other hand, in the rabbits with follicles only, the contrast filling of the tubal vessels was more pronounced than that of the corresponding vessels of an ovary with CL. This finding indicates that a redistribution of blood takes place between the ovary and other parts of the genital tract supplied by the utero-ovarian vascular arcade when the demand for blood to the ovary increases during the luteal phase. The vein draining the ovary was found to receive tributaries from the uterus and oviduct in the form of vessels parallel to the lateral and medial utero-ovarian arterial anastomoses. Thus, in the rabbit, anatomical prerequisites exist for vasoactive substances, such as prostaglandins, to be released from the uterus into the common uteroovarian vein whence they might influence ovarian blood flow and luteal function by constricting the vein (Pharriss, 1970). In the sheep, several experiments indicate the possibility of a 'counter-current' transfer mechanism of prostaglandin from the uterine vein to the ovarian artery (McCracken et al., 1971). A requirement for such a transfer is an intimate anatomical connection between the vessels, which has been found in the sheep (Lee \& O'Shea, 1974). The present study indicates that, in the rabbit, there is a variable relationship between the ovarian arteries and veins, and a countercurrent transfer of luteolytic substances would therefore be less likely in this species.

The present anatomical observations of the vessels should be supplemented with functional studies to determine whether the uterine control of luteal function is predominantly local or systemic in the rabbit.

The authors wish to thank Professor Kurt Ahrén and Dr Sture Stattin and Dr Margareta Norman for valuable advice and assistance. This research was sponsored by grants from The Swedish Medical Research Council (B7403X-2710C), Göteborgs Läkaresällskap and The Faculty of Medicine, University of Göteborg.

\section{REFERENCES}

Adams, D. F., Olin, T. B. \& Redman, H. C. (1965) Catheterization of arteries in the rabbit. Radiology, 84, 531-535.

Ahrén, K., Janson, P. O. \& Selstam, G. (1974) Search for arterio-venous shunts in the rabbit ovary in situ using perfusion of microspheres. 7. Reprod. Fert. 41, 133-142.

ANDERson, L. L. (1973). Effects of hysterectomy and other factors on luteal function. In Handbook of Physiology, Section 7, Vol. II, part 2, pp. 69-86.

Asdell, S. A. \& HAMmond, J. (1933) The effects of prolonging the life of the corpus luteum in the rabbit by hysterectomy. Am. 7. Physiol. 103, 600-605.

Dorrowolski, W. \& HAfez, E. S. E. (1971) The uterus and control of ovarian function. Acta obstet. gynecscand., Suppl. 12.

Duncan, G. W. \& Pharriss, B. B. (1970) Effects of non-steroidal compounds on fertility. Fedn Proc. Fedn Am. Socs exp. Biol. 29, 1232-1239.

Göthlin, J. \& Garter, A. M. (1969) Pelvic angiography in the female rabbit. Investve Radiol. 4, 45-49. Horenstein, R., Lundh, A. \& SJögren, S. E. (1964) The subtraction method. Acta radiol. 2, $264-271$. Lee, C. S. \& O'SheA, J. D. (1974) Observations on the utero-ovarian vasculature of the sheep. $\mathcal{F}$. Reprod. Fert. 36, 459-460. 
McCracken, J. A., Baird, D. T. \& Goding, J. R. (1971) Factors affecing the secretion of steroids from the transplanted ovary in the sheep. Recent Progr. Horm. Res. 27, 537-582.

Novy, M. J. \& Cook, M. J. (1973) Redistribution of blood flow by prostaglandin $F_{2 a}$ in the rabbit ovary. Am. 7. Obstet. Gynec. 117, 381-385.

Pharriss, B. B. (1970) The possible vascular regulation of luteal function. Perspect. Biol. Med. 13, 434444.

Zredses des Plantes, B. G. (1961) Subtraktion. Georg Thieme, Stuttgart. 